\title{
Utilizing active learning strategies to enhance learning in first year university chemistry courses
}

\author{
Lucia Pappalardo \\ Cindy Gunn \\ American University of Sharjah, UAE
}

\section{Introduction}

The American University of Sharjah (AUS), founded in 1997, is a medium sized, co-educational institute following an American curriculum and based in the United Arab Emirates (UAE). AUS offers both graduate and undergraduate degrees and has UAE Higher Education and American Middles States Accreditation, as well as accreditation from other professional bodies including ABET for the College of Engineering. All courses are taught in English. In the 2011- 2012 academic year there were over 84 different nationalities in both the undergraduate and graduate programs. The faculty is also multicultural, with professors, lecturers and instructors from more than 35 different nationalities. As a result of this cultural diversity, students and professors alike are exposed to many different views on teaching and learning.

Many of the students who attend AUS are from the Middle East or the surrounding area. In addition to the local Emirati students, many of the student population come from countries such as Jordan and Syria, but have been born and raised in the UAE. Most of these students come from government high schools, where the language of instruction is Arabic and where there is often an emphasis on a more traditional approach to teaching, i.e., there is more of a focus on content delivery than on how to use that content in everyday life. Many students from countries such as India and Pakistan have also been born and raised in the UAE, and usually attend private schools where the language of instruction is English. In both cases final evaluation is often in the form of high-stakes university entrance exams which encourage rote memorization. Informal feedback from many different students suggests that very little group work or other active learning strategies were employed in high schools. Not surprisingly, when these students start studying at AUS they have to be encouraged to think critically and to actively involve themselves in the learning process.

Another component that can present difficulties for students coming from the government school system, or even from the British school system, is the General Education component of the American curriculum at AUS, whereby all students must take a required number of Arts (Humanities) and Science courses. The General Education program at AUS "complements professional programs by offering opportunities for students to reflect on a diverse and increasingly interdependent world and their place within it" (American University of Sharjah, 2012). Thus, for all students at AUS it is expected that the exposure to courses outside their major will offer them the opportunity to experience a wide range of subjects and models of learning. The attitudes towards the required General Education courses can vary widely amongst the students, with some of them valuing the exposure to these different courses outside their majors while others dread or even resent taking them. Some of the negative attitudes could stem from the fact that students in the government schools specialize in either arts or sciences at the beginning of high school; once the decision has been made, either by the students or by the teachers based on grades and perceived aptitude, students do not take many classes outside their specialization.

Pappalardo, L. \& Gunn, C. (2013). Utilizing active learning strategies to enhance learning in first year university 
In the government schools the science track is seen as the harder of the two tracks and as such, when non-science majors enter AUS some of them experience great difficulty in the Science classes.

Science courses are usually not popular among college and university students worldwide (Hockings, DeAngelis \& Frey, 2008; Kovac, 1999; O'Sullivan \& Copper, 2003; Paulson, 1999). As Cooper (2010) notes, chemistry courses in particular are usually considered hard and tend to have high failing rates. As a result, many college students tend to withdraw from or perform poorly in required first year general chemistry courses. To address this problem numerous educators have expressed the need for a reform of undergraduate General Chemistry courses (Cooper, 2010; Hockings et al., 2008; Paulson, 1999) and several suggestions have been offered for how to enhance general chemistry courses, such as an Activity Model of Inquiry (Marchlewicz \& Wink, 2011), the adoption of a Sense of Narrative (Chang \& Churchill, 2011), and combining science with ethics and politics (McGowan, 2011). To encourage active learning, students are often given group work activities. When working in groups, it is more difficult (though not impossible) for students to be passive participants. The group task allows for sharing of ideas and for students to help each other better understand the material.

Group formation is an issue that many teachers struggle with and can have an impact on the success or failure of the group work assignment (van der Laan Smith \& Spindle, 2007). The groups are either chosen by the students themselves or by the instructor. If the groups are chosen by the instructor the selection can either be random or pre-determined. In the Middle East, many schools and universities are single-sex so in a co-educational institution such as AUS, mixed gender groups could be seen as problematic. However, in a 2007 study (Gunn, 2007) conducted at AUS with 132 undergraduate students (61 males and 71 females), 97 students (47 males and 50 females) said they prefer to work in mixed gender groups, 10 students (eight females and two males) said it did not matter to them, and 22 students (12 females and 10 males), said they would prefer to work in same gender groups. Three students did not answer the question. These results suggest that although AUS is a coeducational institute, it is important to give consideration to cultural attitudes towards mixed gender activities.

Although the traditional lecture is still used in many teaching contexts, and is especially associated with science and technical subjects, there have been numerous calls over the years to provide a more enhanced learning environment for students in all majors (Åkerlind, 2008; Boyer, 1990). Ramsden notes that in contrast to lecturing:

Such methods involve students in actively finding knowledge, interpreting results, and testing hypotheses against reality (often in a spirit of cooperation as well as individual effort) as a route to understanding and the secure retention of factual knowledge. These methods are in sharp contrast to those which concentrate on placing authoritative information before individual students and leaving the rest up to them. $(1992$, p. 152)

One way to engage students is through the use of active learning techniques (Chickering \& Gamson, 1987; Faust \& Paulson; 1998). As Bonwell and Eison (1991) note, when active learning strategies are employed in class, students are engaged in activities such as reading, discussing and writing, rather than passively listening to the instructor. There is less emphasis placed on information transmission and greater emphasis placed on developing student skills.

For non-science students, AUS offers free-electives in chemistry, physics, biology and environmental science. Chemistry courses are usually the least popular, regardless of the professor teaching the class, while environmental science and biology courses prove to be the most popular ones. Students' reasons for not taking chemistry center on the difficulty of the course, which results in the students getting low grades.

Pappalardo, L. \& Gunn, C. (2013). Utilizing active learning strategies to enhance learning in first year university chemistry courses. Learning and Teaching in Higher Education: Gulf Perspectives 10(1). http://lthe.zu.ac.ae 
In order to enhance the students' understanding of chemistry to ultimately help them raise their grades and their interest in the subject, active learning methods were introduced in two sections of the nonscience general chemistry course during the Spring 2012 semester.

\section{Introducing Active Learning Techniques}

This study involved a total of 42 non-science students from the College of Architecture, Art and Design (CAAD) and the School of Business and Management (SBM), who were taking one of their two General Education required sciences courses. There were 24 in class A and 18 in class B. The course is called Chemistry and Everyday Life (CHM 103) and introduces the fundamental principles of chemistry and the role of chemistry in everyday activities. It covers the chemistry of atoms and molecules, chemical reactions, acids and bases, oxidation and reduction, nuclear chemistry and organic chemistry. It explores selected chemicals used in everyday life, including polymers, perfumes, cosmetics, detergents, food components and toxins. The course is not open to science or engineering students.

In previous semesters, these classes have been taught using lectures supplemented with PowerPoint slides or demonstrations on the whiteboard, and some large group discussion based on instructor led question prompts. In Spring 2012, the classes were not delivered in the same format. They varied from $100 \%$ lecturing to $100 \%$ activities, with the majority being $50 \%$ lecturing and $50 \%$ activities. Classes that consisted of $100 \%$ activities were on topics that were well explained by the textbook and could be handled by the students as determined by the instructor.

In-class group activities consisted of discussions, problem solving sessions, student presentations, newspaper/magazine article critiques and web searches. All the activities were graded in terms of three categories: class participation, pre-class quizzes and group activities. A weighting of $5 \%$ of the final grade was given to each category.

Group discussions were designed by asking students to comment on or explain a topic and by posing questions to further their understanding and critical thinking about the topic. In problem solving sessions, students were asked to work together on problems similar to the ones assigned as homework and in exams. Student demonstrations consisted of calling students randomly to the board to show how to solve a problem to the whole class after they had worked on the problem with their group mates. Newspaper/magazine article critiques and web searches consisted of asking the student to search for an article about a topic related to chemistry and then discuss it with the rest of the class.

To provide the extra time needed for the in-class activities, the instructor had to lecture less; and to make sure the material was given due coverage, students were asked to do reading assignments before the topic was covered in class. To encourage students to study, pre-class graded quizzes were given to the students. This technique, adopted from Paulson (1999), consisted of short quizzes at the beginning of class designed to test students on the reading assignments: each question was projected for one minute and the students had one minute to respond. To be successful in the quizzes the students had to study the reading assignments and be on time to class. The response was collected in a notebook that belonged to the student and was collected at the end of quiz, graded and given back to them for the next quiz.

Group work was a large part of introducing active learning techniques. At the beginning of the semester, the students were asked to form groups of four. Since it seemed that the weakest groups were basically repeating from the textbook and not really benefiting from the group discussion activity, in the middle of the semester the instructor formed the groups by trying to mix weak and the stronger students together. This proved to be not very successful because students were much more productive and

Pappalardo, L. \& Gunn, C. (2013). Utilizing active learning strategies to enhance learning in first year university

chemistry courses. Learning and Teaching in Higher Education: Gulf Perspectives 10(1). http://lthe.zu.ac.ae 
interactive when they chose the groups by themselves. During the group work activities, the instructor circulated among the groups to make sure the students were on task and to offer help where necessary; the help offered was not the direct answer to the problems but usually consisted of explaining the concept in a different way or in formulating questions to encourage students' critical thinking. As Burbach, Matkin and Fritz (2004) note, critical thinking is generally viewed as an expected outcome for students in Higher Education but is rarely measured directly. In their study with freshman students in leadership courses, they found significant improvement in the pre and post-tests of the students' critical thinking skills after a semester of employing active learning strategies.

For the problem solving sessions, the problems were projected on the board and students were given a few minutes to solve each problem. The time was not strictly monitored: the instructor moved on to the next problem when all or the majority of students had managed the problem. Timing was not a problem, and usually all the problems prepared for each class were completed by the end of the lecture.

\section{Student Feedback}

At the end of semester students were asked to fill in a voluntary and anonymous survey. 40 students out of 42 filled in the survey, and the results are reported in Table 1 and Table 2 as percentages. Three quarters of the students considered that solving problems in groups had helped them learn the material (Q1 in Table 1). 45\% of the students responded that all the classroom activities were useful (Q2 in Table 1). However, some of the activities were considered to be less useful by a smaller percentage of the students: mainly the two class activities held in the computer labs, followed by the short videos, group discussion/explanations and professor lectures (see Table 1). The students were also asked which format would work best for the course in terms of percentage of time devoted to lecturing and in class activities. The majority preferred a mix of lectures and activities, with the most popular option being $50 \%$ activities $50 \%$ lectures (Q3 in Table 1 ).

Table 1: Students' responses to survey questions.

\begin{tabular}{|l|l|l|}
\hline \multirow{2}{*}{$\begin{array}{l}\text { Q1. Which of the following classroom } \\
\text { activities used recently in your Chemistry } \\
\text { classes have helped you learn best? }\end{array}$} & Solving problems in group & $75.0 \%$ \\
\cline { 2 - 3 } & Group discussions/explanations & $15.0 \%$ \\
\cline { 2 - 3 } & Professor Lectures & $10.0 \%$ \\
\hline \multirow{2}{*}{$\begin{array}{l}\text { Q2. Which of the following classroom } \\
\text { activities used recently in your Chemistry } \\
\text { classes have NOT helped you learn (i.e. } \\
\text { helped you the least)? }\end{array}$} & Solving problems in group & $0 \%$ \\
\cline { 2 - 3 } & $\begin{array}{l}\text { Group discussions/explanations } \\
\text { questions in group }\end{array}$ & $7.5 \%$ \\
\cline { 2 - 3 } & Professor Lectures & $5.0 \%$ \\
\cline { 2 - 3 } & Short videos & $7.5 \%$ \\
\cline { 2 - 3 } & Computer class activities & $10.0 \%$ \\
\cline { 2 - 3 } & Performing short experiments in class & $20.0 \%$ \\
\cline { 2 - 3 } & None (i.e. all were useful) & $5.0 \%$ \\
\hline
\end{tabular}

Pappalardo, L. \& Gunn, C. (2013). Utilizing active learning strategies to enhance learning in first year university chemistry courses. Learning and Teaching in Higher Education: Gulf Perspectives 10(1). http://lthe.zu.ac.ae 
Q3. What format do you think will be best for CHM 103 course? (The percentages indicate the time devoted to each section)

\begin{tabular}{|l|l|}
\hline $100 \%$ Group activities & $7.5 \%$ \\
\hline $75 \%$ Group activities; 25\% Professor Lectures & $30.0 \%$ \\
\hline $50 \%$ Group activities; 50\% Professor Lectures & $40.0 \%$ \\
\hline $25 \%$ Group activities; 75\% Professor Lectures & $22.5 \%$ \\
\hline $100 \%$ Professor Lectures & $0 \%$ \\
\hline
\end{tabular}

The responses of students to the statements S1, S3, S4, S5 reported in Table 2 below reinforce the fact that the students found solving problems in groups helped them learn chemistry. In response to one of the statements on the survey, they responded that explaining problems to other students helped them the best ( $\mathrm{S} 4$ in Table 2). Only twice during the semester as in-class activity, students were asked to design problems similar to the ones solved in class and as homework by using four or five keywords given to them by the instructor. This task proved to be difficult for the students and it is reflected by the least positive response to statement S2. The discrepancy in the responses to the last statement (S6) of Table 2 was interpreted by the authors as caused by the students' lack of knowledge of the meaning of the English word "intimidates". Indeed, a few of them asked the professor about it later. The students were given a series of statements and asked to rank their level of agreement ( $S A=$ strongly agree; $\mathrm{A}=$ agree; $\mathrm{N}=$ neutral; $\mathrm{D}=$ disagree; $\mathrm{SD}=$ strongly disagree; $\mathrm{NA}=$ not applicable).

Table 2: Students' responses to survey statements.

\begin{tabular}{|l|l|l|l|l|l|l|}
\hline & SA & A & N & D & SD & NA \\
\hline S1. I find solving problems in group in CHM 103 helpful. & $\mathbf{5 7 . 5}$ & 37.5 & 5.0 & 0.0 & 0.0 & \\
\hline $\begin{array}{l}\text { S2. I find designing/creating new problem questions in } \\
\text { group in CHM } 103 \text { helpful. }\end{array}$ & 12.5 & 27.5 & $\mathbf{3 7 . 5}$ & 17.5 & 5.0 & \\
\hline $\begin{array}{l}\text { S3. I find other students' explanations help me understand } \\
\text { better CHM } 103 \text { topics. }\end{array}$ & 20.0 & $\mathbf{5 5 . 0}$ & 15.0 & 10.0 & 0.0 & \\
\hline $\begin{array}{l}\text { S4. The group activities helped me learn better by } \\
\text { explaining problems to other students. }\end{array}$ & $\mathbf{5 0 . 0}$ & $\mathbf{4 5 . 0}$ & $\mathbf{2 . 5}$ & 0.0 & 0.0 & 2.5 \\
\hline $\begin{array}{l}\text { S5. Working in groups makes me feel confident of my } \\
\text { abilities. }\end{array}$ & $\mathbf{4 5 . 0}$ & $\mathbf{4 7 . 5}$ & $\mathbf{7 . 5}$ & 0.0 & 0.0 & \\
\hline S6. Working in groups intimidates me. & 5.0 & $\mathbf{2 2 . 5}$ & $\mathbf{3 5 . 0}$ & 17.5 & 17.5 & 2.5 \\
\hline
\end{tabular}

Selected students' (unedited) comments illustrating some of the themes identified are shown below:

Open-ended survey question: Why do you find these activities helpful?

- We practice in class and learn from other class mates, and also for the help the professor provides while solving in groups.

- Because the group activities give an opportunity for students to interact with one another, explain to one another, and discuss material being covered during the lecture. 
- Group members could help each other solve problems because they give more examples and allows you to learn with more than one ways of explaining.

- It helps in practicing the material in class, and understand it better. in addition, it remove any concern about the specific part of the material.

- Everybody works together to solve problems, students know how to explain to each other best. since everyone is involved, its more fun to work together

- Its encourage you to participate with other colleague, and grows on you the spirit of corporation

- You get to discuss the material you have learnt during the lecture. You can ask about parts of the material you don't understand, and help people with things they need help with.

- Explaining concepts and definitions to others also helps me understand them better. Finally, sometimes I think I understood the material when in actual fact I didn't, group discussions provide others with the opportunity to identify your errors and clarify the concepts.

Final open-ended survey question: Do you have other comments in regard to CHM 103 taught by Dr Lucia?

- Actually I enjoyed the the CHM 103 with Dr. Lucia because there were a lot of discussion with the professor herself rather than the discussion with group mates.

- Overall, I enjoyed the class activities and lectures and I think it was a great investment of time since Dr. Lucia is a knowledgeable person who is ready to answer and explain any sort of "on spot" questions. I think she managed to control the class, deliver knowledge, and help us in understanding course materials.

\section{Instructor's Impressions}

Introducing active learning techniques had both positive and negative aspects to it from the instructor's point of view. The positive aspects include improved professor/student and student/student interaction in the class. Based on the authors' experiences, AUS students are reluctant to show when they do not know/understand something and to ask or answer questions in front of the class, thus the group activities were an effective way to address individual students' problem areas because during the inclass activities the professor could clearly see the students' weaknesses and address them in the group and not in front of the whole class. The professor felt more relaxed and more effective in getting the material across to the students. In addition, compared to previous semesters, the professor found that more students visited her office to discuss the class. She felt that the students were more comfortable asking for help as a result of the informal interaction between the students and professor during the group activities. Overall, compared to nine previous sections taught, the students in Spring 2012 showed a better understanding of chemistry as demonstrated in their homework assignments, quiz and test scores.

Although this was a rewarding experience for the professor to cover the required course content in a more creative way, there were two drawbacks. The first drawback has to do with the amount of time to prepare the activities and regularly grade the activities and quizzes - although with more experience of introducing active learning techniques in class the preparation time may be reduced. The second drawback has to do with one of the activities: the students' demonstrations on the board proved to be less useful than the professor had hoped since this was very-time consuming and usually the answers

Pappalardo, L. \& Gunn, C. (2013). Utilizing active learning strategies to enhance learning in first year university 
were not well explained by the students. Some solutions to this drawback would be to rework the assignment, to give the students very clear instructions and to allow students more time to prepare their answers perhaps through homework assignments. As Biggs notes "teachers need to be clear about what they want their students to learn, and how they would manifest that learning in terms of 'performances of understanding'" (1996, p. 363, quotation marks in original). In previous semesters, the students showed whether they understood or not through formal testing avenues. In Spring, 2012, the students were given numerous opportunities to demonstrate their understanding in a variety of different ways through the active learning techniques, some of which were more successful than others.

\section{Limitations of this study}

This was a small scale study and although the results of the data analysis show that both the students and the professor benefited from the introduction of the active learning techniques there were a few limitations to this study. Although there were two classes involved the authors decided not to have one of them serve as a control group. Comparison of results and improved performance was based on the professor's previous experience teaching the same course at AUS for nine semesters. This study involved non-science majors taking a science elective course thus this limits the possibility to do a follow-up study to measure if there was any long term effect on the participants' learning of chemistry.

\section{Conclusions}

It is important to note that although the students commented that they benefitted from having the opportunity for active learning, only $7.5 \%$ of the participants in this study thought that this method of instruction should be used $100 \%$ of the time. Most of the students noted the need for a balance of lectures and active learning activities. An area for further research would be to conduct a larger-scale study to determine if the $7.5 \%$ is representative of the non-science major undergraduate students taking chemistry: i.e., in a larger sample would more students opt for a class based on activities $100 \%$ of the time?

Overall, in spite of the few drawbacks, the introduction of group activities in elective chemistry classes was a successful endeavor. Although Hockings, et al., have argued that "students in introductory chemistry sequences often are not actively involved in the learning process" (2008, p. 290), this small study shows that this can easily be changed with the incorporation of active learning techniques. The students in this study responded favorably to the group work problem solving activities and noted that they learned more when they had the opportunity to explain concepts to their peers. This has an important pedagogical implication for Chemistry professors. By choosing to move beyond the lecture format to help the students engage with the material, the professor was able to utilize "sound teaching strategies [to] encourage students to relate to the subject matter they are studying in a purposeful way" (Ramsden, 1992, p. 150). Given that the subject matter is challenging for non-science majors, the incorporation of active learning techniques allows students to show the areas they need help with in a non-threatening manner. This, in turn, can help encourage the students to take risks and become active, engaged participants in the class.

\section{References}

Åkerlind, G. S.(2008). A phenomenographic approach to developing academics' understanding of the nature of teaching and learning. Teaching in Higher Education 13(6), 633-644. DOI: 10.1080/ 13562510802452350

Pappalardo, L. \& Gunn, C. (2013). Utilizing active learning strategies to enhance learning in first year university 
American University of Sharjah (2012). General Education Program. Retrieved from http://www.aus.edu/info/200228/general_education_program\#.UQJwnb_CaSo

Biggs, J. (1996). Enhancing teaching through constructive alignment. Higher Education, 32, 347-364.

Boyer, E. (1990). Scholarship Reconsidered: Priorities of the Professoriate. New York: John Wiley and Sons.

Bonwell, C., \& Eison, J. (1991). Active learning: Creating excitement in the classroom. ASHE-ERIC Higher Education Report, The George Washington University, School of Education and Human Development, Washington, D.C.

Burbach, M. E., Matkin, G. S. \& Fritz, S.M. (2004). Teaching Critical Thinking in an Introductory Leadership Course Utilizing Active Learning Strategies: A Confirmatory Study. College Student Journal, 38 (3), 482-492.

Chang, J.\& Churchill, D. (2011). Bringing out the "Main Characters" in General Chemistry: Can creating a sense of narrative in the classroom and for the textbook aid long-term memory? Journal of Chemical Education, 88(4), 408-414.

Chickering, A., \& Gamson, Z. (1987). Seven Principles for Good Practice in Undergraduate Education. American Association of Higher Education Bulletin, March 1987. Washington D.C.: Association of Higher Education, p. 3-6.

Cooper, M. (2010). The case for reform of the undergraduate General Chemistry Curriculum. Journal of Chemical Education, 87(3), 231-232.

Faust, J., \& Paulson, D. (1998). Active Learning in the College Classroom. Journal on Excellence in College Teaching, 9 (2), p. 3-24.

Gunn, C. L. (2007). Mixed gender group projects at AUS: Creative Collaboration or Problematic Partnership? Language Teacher Research in the Middle East. Coombe, C.; Barlow, L. Eds. (pp 65-80). TESOL: Alexandria.

Hockings, S. C., DeAngelis, K. J. \& Frey, R. F. (2008). Peer-led team learning in general chemistry: Implementation and evaluation. Journal of Chemical Education, 85(7), 990-996.

Kovac, J. (1999). Student active learning methods in General Chemistry. Journal of Chemical Education, $76,120-124$.

Marchlewicz, S.C. \& Wink, D.J. (2011). Using the activity model of inquiry to enhance general chemistry students' understanding of nature of science. Journal of Chemical Education, 88, 1041-1047.

McGowan, A. H. (2011). Innovation in Science Education: Combining Science with Ethics and Politics. Proceeding of ICERI2011 Conference, 4815-4821.

O'Sullivan, D. W. \& Copper, C. L. (2003). Evaluating active learning. Journal of College Science Teaching, $32(7), 448-452$.

Paulson, D. R. (1999). Active learning and cooperative learning in the Organic Chemistry lecture class. Journal of Chemical Education, 76, 1136-1141.

Ramsden, P. (1992). Learning To Teach in Higher Education. New York: Routledge.

Pappalardo, L. \& Gunn, C. (2013). Utilizing active learning strategies to enhance learning in first year university

chemistry courses. Learning and Teaching in Higher Education: Gulf Perspectives 10(1). http://lthe.zu.ac.ae 
van der Laan Smith, J. \& Spindle R.M. (2007). The impact of group formation in a cooperative learning environment. Journal of Accounting Education, 25, 153-167.

http://dx.doi.org/10.1016/j.jaccedu.2007.09.002 